\title{
Haunted Histories: Time-slip Narratives in the Antipodes
}

\author{
Claudia Marquis
}

In a startling moment in Margaret Mahy's The Tricksters, Harry draws apart from the rest of her family in her attic bedroom in the family beach house, Carnival's Hide. She looks into a mirror and sees her image dismantle, allowing a very different, but nevertheless clearly related figure to emerge. This is a typical event in time-slip stories, with their peculiar interest in the problematic construction of subjectivity. In this case the characters who slip between times are a bizarre trio of brothers who erupt into the more or less ordinary family lives of the Hamiltons, disturbing the modern moment with ancient memories, igniting passions, provoking revelations, raising questions about identity, threatening fragmentation, but finally harnessed in the interests of the ongoing narrative in which Harry's adult life forms.

What makes events in The Tricksters the more sensational is that the slip in time is also a slip between cultures, marking the uneasy connection between contemporary society and New Zealand's colonial past. The tense personal narrative serves to challenge the domestic ground of identity, by reviving otherwise unacknowledged or under-reported pasts, before somehow accommodating them. Time-slipping fantasy literature for children, in the English-speaking tradition, tends to work this way, even in its earliest moments. Such stories constitute a particularly interesting subset of the fantastic, I would argue, as that genre is defined by Tzvetan Todorov, although so much concerned with shaping a material past that modern criticism generally chooses to ignore the fantastic dimension. ${ }^{1}$ It is at least arguable that, as fantastic literature, the time-slip narrative realises to an intense degree the edgy pleasures of psychic and cultural transgression. This kind of fantastic stages vulnerability; but also discovers a whole set of potential histories in the fraught world of a child who is on the way to becoming adult. Often enough, furthermore, it dramatises this liminality by focusing on a socially alienated child, whose experience, therefore lays down a plot that patterns the desires of many. My particular concern is with Australian and New Zealand examples of this subset, Ruth Park's Playing Beatie Bow and Beverly Dunlop's Spirits of the Lake, not least because, in taking up this peculiarly English form, both convert it to distinctively local uses and register local anxieties.
The arrival of time-slip fiction, stories that may be viewed as comprising something like a tamed child's fantastic, is comparatively recent. Philippa Pearce's novel Tom's Midnight Garden, published in 1957, is among the very first; it is also the most remarkable. ${ }^{2}$ For both reasons it may serve as a typifying instance of what has become a significant modern tradition, undergirding discussion of what happens when the tradition is taken up in the antipodes. Tom's holiday plans to build a tree-house with his brother Peter are thwarted when Peter contracts measles; to avoid his being infected, Tom is sent to his Aunt Gwen and Uncle Alan. Dull, tedious weeks stretch ahead - a life sentence - and Tom's response to this quarantine is to turn sullen and uncooperative. His totally unexpected discovery of a garden, an alternative reality to possess and explore, provides a way beyond his misery. Tom's entrance into this late Victorian garden is to all appearances not achieved magically, although it does connect inexplicably to old Mrs. Bartholomew upstairs and the grandfather clock that sits in the hall. In effect, Hatty - Mrs. Bartholomew — takes Tom with her when she dreams of the garden where she played as a child, dreams that appear to recreate the past in the present; the grandfather clock's striking thirteen at midnight suspends time, granting Tom a space where his and Hatty's worlds intersect - the barriers of time dissolve, joining past and present, fantasy and reality — and 'time no longer' exists.

More is involved in these doubled moments. The garden has the power to heal the psychic wounds of both children: Tom, who suffers from being separated from his family, finds himself in the past, while old Mrs. Bartholomew, damaged in the past, is able to live again as Hatty in the garden, experiencing a sort of healing restoration in the present. The exclusiveness of the children's enjoyment of this privileged place marks the way in which Pearce would have the fantastic subvert reality's claim to priority, installing a clutch of ideal values - above all, the imagination - transcending ordinary circumstance. When Tom leaves for home, eventually, in effect he comes home, as his puzzled Aunt Gwen reports: 'Of course, Mrs. Bartholomew's such a shrunken little woman, she's hardly bigger than Tom: but, you know, he put his arms right round her and hugged her goodbye as if she were a 
little girl' (p.218). Those arms encircling Hatty figure the looping action of the story, in affective and diagrammatic terms. Here the fantastic turns transcendent in the civilised collapse of the border between self and other that we know as sympathy, the most pure form of humanity.

In effect, then, the genre allows the child reader to track the time-slipping child character into a past that serves as a play-space, where the child is granted the privilege of independence from the constraints and complications of his or her ordinary experience. In so far as the child is propelled back towards a moment where s/he comes to an understanding of self in part by realising where $\mathrm{s} /$ he comes from, the highly personal narrative opens up a further possibility: understanding of the continuities between generations that compose a larger narrative, the history of the community of family, or even the nation. ${ }^{3}$

What particularly interests me in the time-slip story, however, is that function by which the child is located in the cultural present by being relocated, for a time, in a past that is remarkable, paradoxically, by its apparent insignificance. The line of such a narrative is not that of adventure or romance, nor that of fantasy - the marvellous, as Todorov terms it. The effect of this excursion is to acquaint the child — character and reader — with history as a lived experience, lived as it logically cannot be, for sure, but also lived as closely as if it were deep in memory. The modern scholars Tess Cosslett and Valerie Krips have argued persuasively for the tradition's modern origin in post-war social reconstruction, undertaken at the level of social welfare, but also at a cultural level, in the reformation of the social imaginary. Cosslett, indeed, draws on Raphael Samuel's Theatres of Memory, which charts the formation of a new sense of the past, in which history no longer comprises 'the biography of great men but rather the record of everyday things'(Samuels, 1996, p.193). This is a history that is commonly made visible in objects. Krips attaches this modern history to the Festival of Britain, 1951, as an exemplary moment, and speaks of the re-creative pleasurein-the-past afforded by such re-enactment events as a 'form of entertainment' (Krips, 2000, p.50). It is difficult to see how it could be otherwise. My particular concern, however, is with the fictive operation by which the re-created past is presented: time is re-conceived in spatial terms, which, of course, gives room to objects. Raphael Samuel puts this in slightly different terms: 'Instead of heredity it offers a sense of place' (Samuels, 1996, p.246). Time-slip fiction typically delivers a past to its children, character and reader, a world that radically extends the world of quotidian reality, by peeling away the present, only to disclose it again in an equally valid form, that which we know in our rational lives as the past. The modern, children's fantastic works this way - not by having some variety of supernatural challenge the primacy of ordinary reality, but by setting past and present in tension, before looking to relax this condition by harmonising worlds and moments.

The world of the past in these books, that is to say, has all the extension of scene. In the earlier, Victorian generation of time-slip stories, the scene of the past tended to be reduced, as it were, to a few representative objects that typically migrated across time, disconcertingly. The modern time-slip story, by materialising the past, giving the past the status of something like memory, arguably re-grounds culture, honouring a sense of national, even racial inheritance, although they largely steer clear of monuments and grand events. In this they seem to bring to realisation a different sense of history again, or rather, as Samuel puts it, 'a whole new family of histories' — in effect arguing for an understanding that taught history is no more valid or authentic than these historical fictions with their minor subjects. Philippa Pearce's time-slip story of Tom's midnight garden employs the techniques of the fantasist, to challenge standard historiography, where the historical subject is subject by virtue of status and where status has something to do with the teleological reach of the historian's vision. This minor fantastic tradition, that is to say, may operate as what Linda Hutcheon calls 'historiographical metafiction' (Hutcheon 1988, pp.105-23). Almost, for sure, despite itself.

The novels by Park and Dunlop, for all the interest they share with their English precursors in child characters who are in some respect damaged, or at least alienated within their present worlds, deal very differently with the pressure history may be seen to place on the formation of subjectivity - mostly because they must take account of a history that is constructed in radically different ways. They are still acutely interested in 'a sense of place' and in 
bringing personal history and the history of the community into alignment, but for them the difficult achievement of social identity in terms of relations that run deep within the community necessarily struggles with oppositions that remain unresolved in the local history. The cultural story in itself involves radical displacement and, all too often, disabling encounters with other cultures.

In Playing Beatie Bow, as in Tom's Midnight Garden, the time-slip moment comes with the striking of the clock, in this case the Town Hall clock, at 5.30, as Abigail chases the little furry girl, Beatie Bow herself, along Harrington Street, 'a queer old road, not much used now, all different levels' (p.31). She chants a line from the game that has first drawn her into Beatie's company, 'O Mudda, what's that, what can it be?' - not what you expect to hear on a late twentieth-century, Sydney street - and, before she knows it, she's in a world of gas-lamps, hard-driven horses and foul-mouthed cabbies. 'Dreaming!' she thought. 'That's all. I'm dreaming.' The world in which she finds herself is threatening - maybe not threatening as Todorov's fantastic other world typically is, but threatens nevertheless, with its 'foreign-looking women in long aprons' and children who are 'more dirty and ragged and evil-looking than she had imagined children could be' (p.32).

In Beverly Dunlop's Spirits of the Lake, things go differently, although, once more, there is a clock, even if this one does not work at all, hasn't struck for years; as a 'story clock', it still operates very efficiently as a signifier of an enabling temporal instability. Again, Paul, the twelve-year old hero of the story, thinks he must be dreaming, when he bangs his leg, hard, blacks out and wakes up in the middle of the nineteenth-century Maori Wars. In his case he thinks that this may be just the latest in the line of nightmares that have recently plagued him. The alternative? His options are those of the fantastic, again as typically written for children:

What was happening? thought Paul. Was this another of his nightmares? Was he going mad? Who were these ghost-like people? He shuddered. There was evil here - he could sense it - and it seemed a battle to the death. (p.32)
The intensity of his anxiety arises from acute uncertainty in face of a world that cannot be, but which impresses itself upon his senses as being quite as real as his familiar world at home. Paul's answer, not to be found among those fantastic questions, is literally to read his experience, to read the violence he witnesses as film: 'Paul wanted to turn away, sickened at the killing, but somehow he couldn't. It was as if he were watching a film - flash, flash went the camera; it wasn't real, he told himself firmly, it wasn't real' (p.33). But the intensity of the denial points up the fact that, for him, nothing is more real.

Oddly, Abigail comes to a similar conclusion, in Playing Beatie Bow, when she wonders how far dreaming could have explained her experience:

Why didn't I think I'd got into some street where the television people were shooting a film or something? But she knew she hadn't. From the first minute, as she lay dazed on the cobbles, she knew that she was real and the place was real, and so were the people in it.

(p.33)

What Abigail sees is a familiar world, but one that is utterly transmuted: 'The houses were like wasps' nests, or Tibetan houses as Abigail had seem them in films, piled on top of each other, roosting on narrow sandstone ledges' (p.33). As in Tom 's Midnight Garden, time, however problematic, becomes known in emphatically spatial terms, as the creation of scene. This reworks the characteristic structures of the fantastic, as Todorov describes them, that result in sustained ambiguity, where the protagonist - and the reader - hesitates over the question of reality, this world or that, because both seem real enough, These stories do open out into an other world, and the question where reality lies is one dimension of their attractive power.

In Abigail's case, her new world is still Sydney, still the Rocks, still Argyle Street, but she does not recognise it, 'although she had walked up that street a hundred times': 'Stone steps ran up one side of the Cut, and on the other two tottering stairways curled upon themselves, overhung with vines and dishevelled trees, and running amongst and even across the roofs of indescribably shanties like broken-down farm sheds' (p.34). Truly a scene. We even 
get the street-cries, or as Park puts it, 'the sounds of the nineteenth-century Rocks': 'Tripe, all 'ot and juicy! Cloes prarps! Windsor apples! Rag'n' bones, bring 'em out!' (p.54).Abigail is especially exercised by the lack of a shower and, in consequence the modern misery of her unwashed hair, so she gets a lesson in local, nineteenth-century life: 'Our linens boiled in the downstairs copper every Monday, rain or shine, and hung out to bleach in the yard. And our outer clothes are sponged regularly every month with vinegar or ivy water, which is a fine cleanser, and better than the ammonia some use' (p.67). It is beautifully done. Vignettes pulled together by Abigail's reluctant presence into an imaginative capture of past times - no less reenactment history than that produced in novels within the English tradition. It may be 'make-believe', but, by virtue of the sensational possibility opened up by the fantastic, it becomes 'living history', in Raphael Samuel's phrase, however distant from the official, or formal narratives to which we more normally accord the status of 'history'.

Nevertheless, if it is 'living history', precisely by remembering lives that typically get forgotten, this kind of narrative is itself selective: it can only remember so much. If Abigail discovers a society she could not have imagined, the fiction works to recover an earlier version of ourselves, a contact with a time so remote that this renewal constitutes a form of magic: marked poverty, amazing kindness, the threat of sexual violence. Still more interesting, perhaps, is the harking back of the book's nineteenth-century, colonial Australian society in turn to a still earlier British society and culture, in the Orkneys, where the fey and the prophetic were vital factors in life. The reconstruction of an imaginary past that forever anticipates futures, then, itself serves to mirror the complicated backwards gaze of the primary story.

This is where the effects of the novel's action must come into question. The to-and-fro of its play with time composes a story that works out the shifting, psychic drama of adolescence, in which the stirrings of sexual attraction finds a most peculiar legitimation, by promising a future that seems to be secured by reference to the past. But this passage into mature subjectivity comes at some cost. The novel incorporates into itself a double reconstruction of the past, both speaking of the problematic impact of colonial heritage. It all works in the fashion of the palimpsest, where text is written over text; correlatively, in such cases, text may be traced under text and sometimes interferes with it; likewise in the fantastic, story may be tracked or read through story, as if they can occupy the same space, motive in one serving to prompt action in the other. In this case, however, the complicated family history also serves to occlude the larger colonial history that good Sydney society does not like to tell, the story of settler relations with the aborigines who barely rate a mention here. As Clare Bradford has repeatedly shown, this is a history of invasion, accommodated by white authors in variety of textual moves that in general discount the singularity of the aboriginal experience and the historical depth of their relations with the land (Bradford, 1997). In the case of Playing Beatie Bow, it is impossible to see through to this most local history, partly because of the book's double anchoring of the legitimate past in a European moment; partly because the narrative dynamic of the magical story operates, as in other time-slip stories, to invest domestic order - the love story — with irresistible power.

The absence of the indigene seems more noteworthy if one puts alongside Park's novel another that is equally concerned with home and family, Beverly Dunlop's New Zealand story, Spirits of the Lake, which works out its generic problem of personal identity in an exceedingly tense engagement with a colonial past, in this case represented by events in the Maori Wars. Again it looks like re-enactment history:

Nearby, Paul saw what looked like the strong
palisades of a Maori pa. The crack and flash of
gun shot spat through narrow openings in the
defence. Itwas a paunder siege, Paul realised-he
remembered pictures he had seen in a historybook
back at home, pictures showing how a Maori pa
would have been defended. (p.33)

We remain conscious, however, of the ideological arc of such a story; it shows up inadvertently, in the authenticating explanation for Paul's recognising the reality of what he sees - he has seen like things in school books. This reverses the move by which indexical character of a photograph, or, indeed a picture, secures its iconic function. 
What concerns me most in Dunlop's novel is the double investment of the adult in such fiction, but also the problematic engagement between white author and black subject - Clare Bradford asks of a not dissimilar fiction in Australia whether it is homage or appropriation. The ideologically driven history of the novel's events is largely absorbed in the crossover between the child and the colonised but indigenous people, figured in a convergence of their imagined locations within their shared world. This level of identification comes very close to the typical failure of fantasy, as Rosemary Jackson describes it, when it articulates 'a longing for imaginary unity, for unity in the realm of the imaginary,' and expresses a 'desire for an absolute, for an absolute signified, an absolute meaning' (Jackson, 1981, p.179). There seems to me no question that, for all its sharpness, Playing Beatie Bow does indeed function this way. What draws Abigail into nineteenthcentury Sydney is a kind of psychic gift, one she possesses by association rather than fact, but a gift that is explained strictly by reference to the origins of the story found not in colonial Sydney but in the Orkney isles, the place of the Talliskers, some of whom possess the gift of prophecy. Abigail moves to and fro on the strength of prophecy. And that imaginative power is fused in the story to her own need for love, discovered at the end of the story, when, as an eighteen year old, she meets and instantly, mysteriously, knows the great great grand son of the family in which she first registered love's force. A mystical perception of the natural world and human relations is no less true of Spirits of the Lake; the question is, whose interests are served?

If fantasies written from a religious or magical base permit such unities, according to Rosemary Jackson, no such ready identification may be fully available where there is no belief to provide the solvent: 'longings for otherness are apprehended as impossible, except in parodic, travestied, horrific or tragic form' (Jackson, 1981, p.179). In the New Zealand story, the story of Paul, time-slipping adventures bring him face to face with most disabling fears — which might suggest that Dunlop is struggling to find her way through to a fiction that does not settle for unities. On the other hand, the fears seem so stagey, so stage-managed, that the truth of the story seems rather to lodge in a familiar modern, postcolonial desire - to invest a dominant settler society with the spiritual authority accorded the indigenous, but largely displaced, people. The desire for an authenticating contact with the past is not restricted to Maori and New Zealand, of course, but it is very marked in this case. Spirits of the Lake may be an involved tale, a latterday 'Robinson Crusoe' and 'Time Machine' all in one, but it also displays the impurity of its desires in its quest for an origin that can be discovered only by a child - and found only in a mystical, Maori sense of the land. The line of the adventure only fades out, in fact, when the twelve-year old hero learns that he himself can claim a part of this Maori heritage through the grandmother he has never known. Perhaps this makes the tale another fantastical reflection of an experience of discovery and recovery with which many New Zealanders are familiar — what Raphael Samuel describes as 'ancestor worship.'

In conclusion, I want to propose a different angle on such a story, one that at least allows it a certain ambivalence, based in the distinction I have been drawing between history and memory. Memory is affective; the new history of tales of this kind gets to be 'living history' because of their interest in discovering the past as an act of understanding, in the body itself, rather than as a body of knowledge.

What is being engineered in such historiographical fictions, perhaps, is the later products of trauma, not so much memories as memory look-alikes - yet definitely still memory-work. It seems to me, indeed, that this is not unlike what Marianne Hirsch calls 'postmemory', although Hirsch is concerned almost exclusively with the no doubt deeper, certainly more destructive trauma of the Holocaust. What postmemory looks for is, in Eva Hoffman's phrase, a 'sense of living connection' to the suffering endured in an originary violation (Hirsch, 2008, p.103); Hirsch tends to find this working through photographs; what I am suggesting is that in certain circumstances, certainly in a book like Spirits of the Lake, that living connection can be discovered in the vivid re-present-ation of a violent past. In the case of Spirits of the Lake, this is all too evident. What postmemory acknowledges is the manifest fact that it operates at a remove, that it is the concern, the obsession of a later generation, a second generation and its affiliates. We are all potentially affiliates. What Hirsch sees in the action of postmemory is not an act of identity so much as 
a structure of 'inter and trans- generational transmission of knowledge and experience.' Eva Hoffman speaks of memories that do not depend like individual or even collective memories on immediate connection with the event itself, but work indirectly, through mediating texts that nevertheless give knowledge a compellingly immediate force. The event, then, may be remembered by means of the stories, images and behaviours among which the later generation grew up; they work not so much by recalling the event as by 'imaginative investment, projection and creation' (Hirsch, 2008, pp.206-7).

Playing Beatie Bow seems to guard against recognition of a problematic colonial past; in that sense, for all its re-creative memory, it is an amnesiac text. To my mind, Spirits of the Lake also proves profoundly suspect, because of the authorial longing by which it is driven, but Beverly Dunlop does seem to have registered an experience of great force, impossible to leave out of memory's work. However one deals with it, the postcolonial inheritance is trauma, whether the trauma of the Middle Passage, or that which stemmed from like assaults on the colonial world's indigenous peoples. Valerie Krips reports a programme of instruction that put British schoolchildren through re-enactment of the evacuation from war-torn London-metropolitan trauma-designed to give the children access to that disturbing history as a form of reality, engaging them immediately in drama in order that the past should be 'really understood' (Krips, 2000, p.78). It is easy to distrust such a programme, but interesting to find such concentrated effort going into laying down memories of an event that makes a claim to be remembered not because it concerned some adult, male, heroic enterprise, but because it constituted something close to cultural trauma, in which all share. The antipodean time-slip fiction may be less programmatic, but, I suggest, it too invests in no safe relationship with the past, but in something more taxing-for all its pleasure in the historical moment, it articulates anxiety that puts the present into question, not so much child's play as games of the dark.

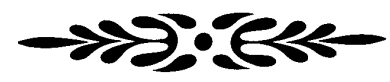

\section{NOTES}

1. Todorov's seminal argument in The Fantastic has seldom been given any weight in critical discussion of children's fantasy, even where this fantasy clearly does seem to set up the structured ambivalence that is for Todorov the condition of the fantastic; it is also true that the children's fantastic has not even been noticed by scholars of the adult tradition.

2. It is difficult not to find in them a kind of re-visioning of the much earlier line of time fantasies associated with Nesbit and Kipling. See Locherbie-Cameron, 1996, pp.45-61.

3. Humphrey Carpenter (1985, p.218) notes that a very high proportion of children's books written between 1950 and 1970 are finally concerned with maturation, often in relation to past of some kind, mythic or actual. See also Cosslett, 2002, pp. 243-53.

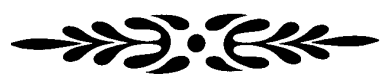

\section{REFERENCES}

Bradford, C. (1997) 'Representing indigeneity: aborigines and Australian children's literature then and now', Ariel 28, 89-99.

Bradford, C. (2001) Reading Race: Aboriginality in Australian Children's Literature. Melbourne, Melbourne University Press.

Carpenter, H. (1985) Secret Gardens : A Study of the Golden Age of Children's Literature. Boston, Houghton Mifflin.

Cosslett, T. (2002) "“History from below": time-slip narratives and national identity', The Lion and the Unicorn 26, 243-53.

Dunlop, B. (1988) Spirits of the Lake. Auckland, Hodder and Stoughton, 1988.

Hirsch, M. (1997) Family Frames : Photography, Narrative, and Postmemory. Cambridge, Mass., Harvard University Press. 
Hirsch, M. (2008) 'The generation of postmemory', Poetics Today 29, 103-28.

Hutcheon, L. (1988) A Poetics of Postmodernism: History, Theory, Fiction. New York, Routledge.

Jackson, R. (1981) Fantasy: The Literature of Subversion. London, Routledge.

Krips, V. (1999) 'Presenting the past', Signal 90, 176-86.

Krips, V. (2000) The Presence of the Past: Memory, Heritage and Childhood in Post-War Britain. London, Routledge.

Locherbie-Cameron, M. (1996) 'Journeys through the amulet: time-travel in children's fiction,' Signal $79,45-61$.

Manlove, C. (2003) From Alice to Harry Potter: Children's Fantasy in England. Christchurch, N.Z., Cybereditions.

Park, R. (1987) Playing Beatie Bow. Harmondsworth, Penguin.
Samuel, R. (1996) Theatres of Memory. London, Verso.

Todorov, T. (1980) The Fantastic: A Structural Approach to a Literary Genre.

Ithaca, Cornell University Press.

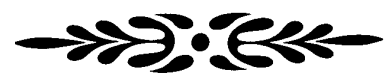

\section{BIOGRAPHICAL NOTE}

Claudia Marquis teaches Adolescent Fiction, African and Caribbean Literature and Renaissance Literature at the University of Auckland. She has published several articles on Jamaica Kincaid and other West Indian writers, as well as New Zealand children's fiction. Her current research includes book length studies of Imperial fiction and of Victorian fantasy writing for children.

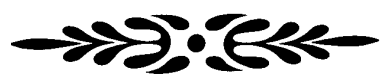

